Article

\title{
Size and Shape-Dependent Antimicrobial Activities of Silver and Gold Nanoparticles: A Model Study as Potential Fungicides
}

\author{
Francis J. Osonga ${ }^{1}$, Ali Akgul ${ }^{2}$, Idris Yazgan ${ }^{3}$, Ayfer Akgul ${ }^{4}$, Gaddi B. Eshun ${ }^{1}$, Laura Sakhaee ${ }^{3}$ \\ and Omowunmi A. Sadik ${ }^{1, *}$ \\ 1 Sensors Mechanisms Research and Technology Center (The SMART Center), Chemistry and Environmental \\ Science Department, New Jersey Institute of Technology, University Heights, 161 Warren Street, \\ Newark, NJ 07102, USA; fosonga1@binghamton.edu (F.J.O.); gbe4@njit.edu (G.B.E.) \\ 2 Department of Sustainable Bioproducts, College of Forest Resources, Mississippi State University, \\ Starkville, MS 39759, USA; aa1116@msstate.edu \\ 3 Department of Chemistry, Center for Research in Advanced Sensing Technologies \& Environmental \\ Sustainability (CREATES), State University of New York at Binghamton, \\ P.O. Box 6000 Binghamton, NY 13902, USA; iyazgan1@binghamton.edu (I.Y.); lsakhae1@binghamton.edu (L.S.) \\ 4 Department of Basic Sciences, College of Veterinary Medicine, Mississippi State University, \\ Starkville, MS 39759, USA; aa1625@msstate.edu \\ * Correspondence: sadik@njit.edu
}

Academic Editors: Adeyemi S. Adeleye and Yuxiong Huang

Received: 30 April 2020; Accepted: 3 June 2020; Published: 9 June 2020

\begin{abstract}
Plant-based pathogenic microbes hinder the yield and quality of food production. Plant diseases have caused an increase in food costs due to crop destruction. There is a need to develop novel methods that can target and mitigate pathogenic microbes. This study focuses on investigating the effects of luteolin tetraphosphate derived silver nanoparticles (LTP-AgNPs) and gold nanoparticles (LTP-AuNPs) as a therapeutic agent on the growth and expression of plant-based bacteria and fungi. In this study, the silver and gold nanoparticles were synthesized at room temperature using luteolin tetraphosphate (LTP) as the reducing and capping agents. The synthesis of LTP-AgNPs and LTP-AuNP was characterized by Transmission Electron Microscopy (TEM) and size distribution. The TEM images of both LTP-AgNPs and LTP-AuNPs showed different sizes and shapes (spherical, quasi-spherical, and cuboidal). The antimicrobial test was conducted using fungi: Aspergillus nidulans, Trichaptum biforme, Penicillium italicum, Fusarium oxysporum, and Colletotrichum gloeosporioides, while the class of bacteria employed include Pseudomonas aeruginosa, Aeromonas hydrophila, Escherichia coli, and Citrobacter freundii as Gram (-) bacteria, and Listeria monocytogenes and Staphylococcus epidermidis as Gram (+) bacterium. The antifungal study demonstrated the selective size and shape-dependent capabilities in which smaller sized spherical $(9 \mathrm{~nm})$ and quasi-spherical $(21 \mathrm{~nm})$ AgNPs exhibited $100 \%$ inhibition of the tested fungi and bacteria. The LTP-AgNPs exhibited a higher antimicrobial activity than LTP-AuNPs. We have demonstrated that smaller sized AgNPs showed excellent inhibition of $A$. nidulans growth compared to the larger size nanoparticles. These results suggest that LTP-AuNP and LTP-AgNPs could be used to address the detection and remediation of pathogenic fungi, respectively.
\end{abstract}

Keywords: luteolin; silver nanoparticles; luteolin tetraphosphate; gold nanoparticles; antimicrobial; remediation; fungicide; fungi 


\section{Introduction}

The recent advances in nanotechnology are directed towards developing better techniques to control and eliminate diseases at the nanoscale level using engineered metal nanoparticles (MNPs) [1]. Antimicrobial activity of MNPs have received significant attention because nanoparticles possess a high surface-area-to-volume ratio and a platform to interact with microbes such as bacteria, viruses, and fungi. The rising cases of resistant bacteria strains due to antimicrobial drugs have led to the need to formulate drugs that can combat resistant bacteria and fungi [2-5].

Nanomaterials are promising candidates with numerous applications in diverse fields. Some metallic nanomaterials serve as bactericidal and bacteriostatic agents. The application of AuNPs is well-suited for biological systems due to their unique physio-chemical properties. It is worth noting that AuNPs possess the ability to undergo localized surface plasmon resonance (SPR), in the presence of light. As a result, a strong SPR band of AuNPs can be optimized to generate a color change [6]. This basis creates a platform for using AuNPs for microbial sensing, biocompatibility, and drug delivery studies [7]. The focus of utilizing AuNPs for controlling pathogenic microbes has received considerable efforts. Bindhu et al. reported the antibacterial activity of AuNPs against Gram-positive (S. aureus) and Gram-negative pathogens (P. aeruginosa) [8]. It was noted that the bactericidal effect of AuNPs possessed an appropriate smaller size as the platform for interacting with the microorganisms [6-8].

Furthermore, Chen et al. reported the effects of Au NPs for the size within the range of 8-37 nm and 3-100 nm on mice studies. It was revealed that the AuNPs with 8-37 nm were more toxic, while AuNPs with sizes between 3-100 nm were less toxic. The toxicity of AuNPs can be attributed to synthetic methods and the use of organic reducing and capping agents during the NP synthesis. It is clear that smaller sized AuNPs are more toxic due to the lower surface area [7].

Furthermore, nano-silver presents several advantages as antimicrobial agents. They possess a very high activity against a broad range of microbes. At lower doses, silver presents low toxicity toward humans and is relatively inexpensive [3]. Silver nanoparticles (AgNPs) have been reported as protective agents for cellular systems while inhibiting microbial growth. The antibacterial activity of nanoparticles has been reported, but their mode of action has been suggested. Several reports on the mechanistic mode of action of silver nanoparticles focusing on the effects of AgNPs has led to effective eradication of the target microbes. Liu et al. reported the possible mechanisms of AgNPs toxicity to bacteria by proposing that the AgNPs adhere to the bacteria surface and affect the membrane function [9]. The silver atom is inert and stable, but it becomes reactive when it assumes an oxidation state of +1 . The silver ions $\left(\mathrm{Ag}^{+}\right)$bind to proteins in the plasma and nuclear membrane, forming a complex that leads to structural changes in the membrane $[10,11]$. Antimicrobial $\mathrm{Ag}^{+}$are also released via the dissolution of AgNPs. The $\mathrm{Ag}^{+}$ions react non-selectively with electron-donating groups such as thiols, hydroxyls, imidazoles, and phosphates [1]. AgNPs accumulate on the surface of the bacteria and form aggregates. As a result, the AgNP creates perforations in the cell wall, disrupting the integrity of the membrane, which leads to cell death [12].

AgNPs are also believed to exhibit antibacterial activity by triggering the formation of reactive oxygen species. These species then interact with the glycoproteins on the cell wall before being transferred into the cytoplasm, where they show major antibacterial activity [13]. Pal et al. reported a comparative report on how the shape of the AgNPs affects the activity against gram (-) bacterium, E. coli. Spherical AgNPs (Cubo- octahedral, or quasi-spherical shapes) (100) facets showed less antibacterial activity in comparison to the triangular (111) facets of AgNPs. Shape [14] and size [15] of the nanoparticles can make a difference even in the case of the nanoparticles possessing the same area-to-volume ratio. Apart from size and shape, surface modification and heterogeneity affect AgNPs' antibacterial capability. A recent study reported that surface modification of AgNPs introduces a physical mechanism for antibacterial activity in addition to their inherent biological interference capability; silver-stearate NPs prevent the microbial attachments, including bacteria and fungi, to the food [13].

Flavonoid Luteolin $\left(3^{\prime}, 4^{\prime}, 5\right.$, 7-tetrahydroxyflavone) is a glycosylated polyphenol, which is widely distributed in fruits and vegetables such as oranges, cabbages, and spinach. In literature, Luteolin 
is known to possess medicinal properties, which include its anti-inflammatory effects, antioxidant and anticancer effects against lung, skin, liver, and cervical cancers [15,16]. Luteolin also can inhibit proliferation and induced apoptosis of prostate cancer cells both in vitro and in vivo [15].

Nanoparticles have become a vital vehicle for the delivery of cancer therapeutics with high bioavailability, high efficacy, and improved permeability and retention effects. However, the solubility of Luteolin in water is poor, and this limitation has hindered the intravenous delivery of Luteolin. Also, Luteolin has previously been shown to alter the permeability of the bacterial cell wall without destroying it. Its antibacterial activity on S. aureus is believed to occur by blocking protein synthesis through interference with DNA enzymes such as DNA topoisomerase I and II [17]. Its molecular activity was also reported for amoxicillin-resistant $E$. coli because it can alter the membrane permeability and interfere with protein synthesis, thus limiting the required enzymes to fight against the noxious stimulus [18]. In this study, Luteolin was converted into a novel, water-soluble Luteolin tetraphosphate (LTP) derivative that was employed to synthesize the silver and gold nanoparticles as reported in our previous work [19].

The goal of this work is to investigate the detection and remediation of pathogenic fungi that lowers the yield of vegetable and fruit crops. Hence, this study revealed that when LTP is utilized as the reducing and capping agent in the synthesis of Ag and Au MNPs, the resulting Luteolin tetraphosphate (LTP)-mediated nanoparticles exhibit unique antifungal and anti-spores' characteristics. We found that LTP- gold nanoparticles did not provide high antimicrobial activity. In contrast, the LTP-silver nanoparticles (LTP-AgNPs) showed a very promising shape and size-dependent antimicrobial activity against both Gram (-), gram (+) bacteria, and the fungi A. nidulans, T. biforme, F. solani, P. italicum, and C. gloeosporioides.

\section{Results}

\subsection{Synthesis and Characterization of LTP-Derived AgNPs and AuNPs}

The synthesis and Physico-chemical characterization of AuNPs and AgNPs have been already reported in our previous work [19]. In this work, AuNPs and AgNPs were synthesized by using Luteolin tetraphosphate (LTP), which acted as a reducing and capping agent. The transmission electron microscopy (TEM) micrographs for AuNPs exhibited majorly spherical nanoparticles, as shown in Figure $1 \mathrm{a}(\mathrm{A}-\mathrm{F})$. The TEM images and corresponding histogram show AuNPs of the size distribution of $9,10,15,16,26$, and $28 \mathrm{~nm}$. The role of LTP as a reducing agent and capping agent was demonstrated by the formation of dispersed AuNPs (Figure 1a) with sizes ranging from 9 to $28 \mathrm{~nm}$, which were stable for eight months [19]. The synthesis of anisotropic nanoparticles ( $99 \%$ nanocubes) as reported in our previous work [19] was observed by reacting different concentrations of $\mathrm{HAuCl}_{4} \cdot 3 \mathrm{H}_{2} \mathrm{O}$ with $600 \mu \mathrm{L}$ of LTP at a mole ratio of 1:2; 2:3, and 5:6 (Figure 1a (E) and Figure S1D). The TEM images confirmed the formation of gold nanocubes (AuNCs), as shown in Figure 1 and Figure S1, with a size distribution of 16, 30, and $22 \mathrm{~nm}$. TEM micrographs of LTP-AgNPs are presented in Figure $1 \mathrm{~b}$ and Figure S1B,E,F) with a size distribution of 16, 20, and $22 \mathrm{~nm}$. The TEM images revealed that the AgNPs were dispersed and were spherical and quasi-spherical in nature with an average diameter size of 12, 30, 36, $32 \mathrm{~nm}$ [Figure $1 \mathrm{~b}(\mathrm{~A}-\mathrm{D})$ ] and 9, 21, and $37 \mathrm{~nm}$ Figure S1B,E,F), respectively.

Figure 2A shows XRD analysis of AuNPs depicting four characteristic diffraction peaks at $2 \theta=38.19^{\circ}, 44.46^{\circ}, 64.60^{\circ}, 77.75^{\circ}$, which could be indexed to (111), (200), (220), and (311) peaks representing characteristic diffraction of elemental metal $\mathrm{Au}^{0}$, which confirmed the formation of crystalline AuNPs ( JCPDS card No.04-0784) [20-22]. The EDX spectrum (Figure 2B) confirmed the formation of $100 \%$ elemental gold since copper originates from the TEM copper grid. 

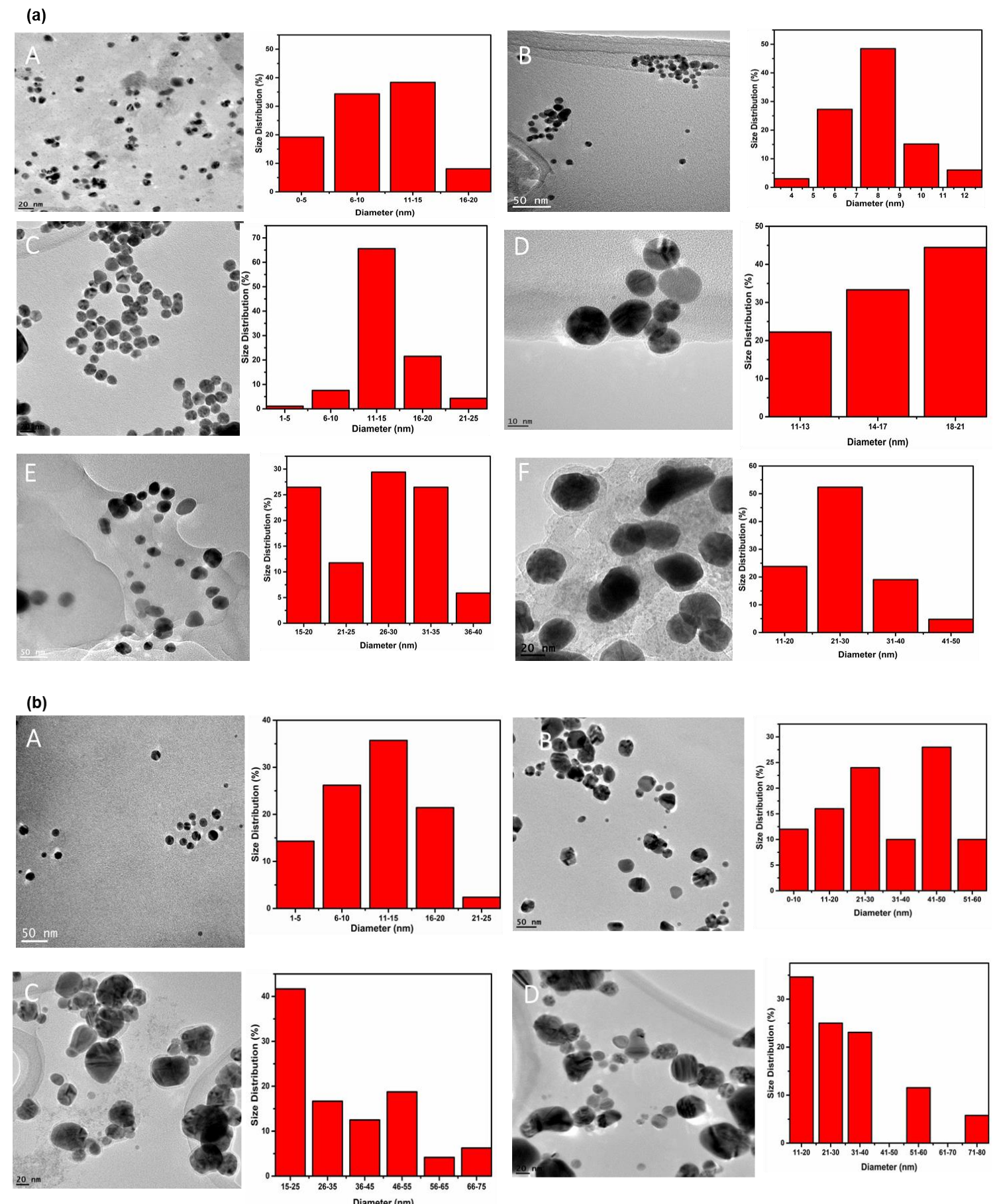

Figure 1. (a) TEM micrographs and corresponding histograms for luteolin tetraphosphate derived gold nanoparticles (LTP AuNPs) A (9nm); B (10 nm); C (15 nm); D (16 nm); E (26 nm); F (28 nm). (b) TEM micrographs and corresponding histograms for luteolin tetraphosphate derived silver nanoparticles (LTP-AgNPs) A (12 nm); B (30 nm); C (36 nm) and D (32 nm). 

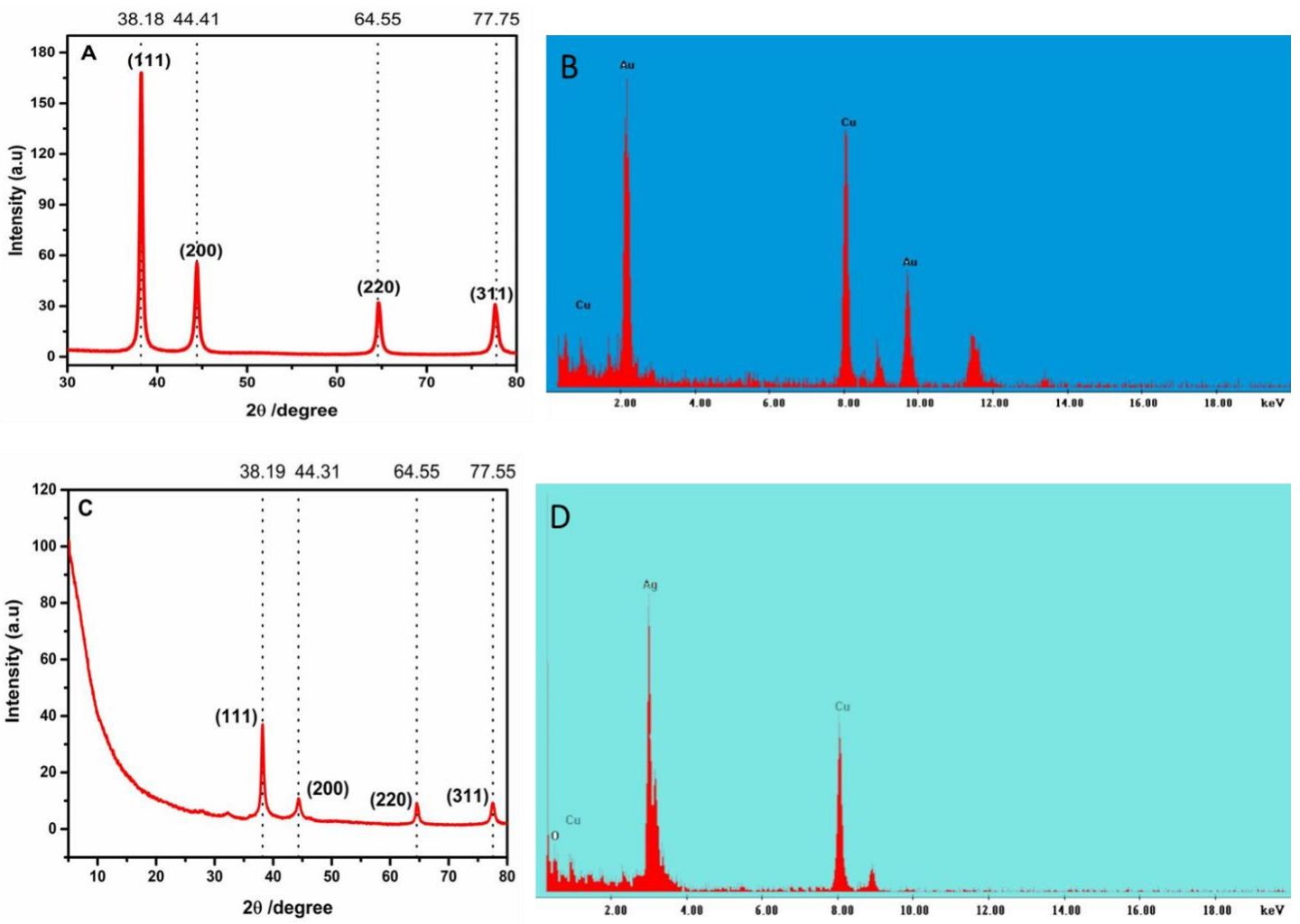

Figure 2. XRD patterns of AuNPs (A) and AgNPS (C); Energy-Dispersive X-ray Spectroscopy (EDX) spectrum of AuNPs and AgNPs (B) and (D), respectively.

Figure $3 \mathrm{C}$ shows the results of XRD data exhibiting four characteristic diffraction peaks at $2 \theta=38.19^{\circ}, 44.46^{\circ}, 64.60^{\circ}, 77.75^{\circ}$, which could be indexed to (111), (200), (220), and (311) peaks representing characteristic diffraction elemental $\mathrm{Ag}^{0}$ and are consistent with standard data file JCPDS No. 04-0783 [23-27].

It is worth noting that in addition to spherical AgNPs, larger quasi-spherical AgNPs were also formed with an average diameter size of 21 and $37 \mathrm{~nm}$, as shown in Figure S1E,F). Energy-Dispersive X-ray Spectroscopy (EDX) was performed on TEM in order to carry out an elemental analysis. The peaks of $\mathrm{Cu}$ normally occur since they are obtained from the TEM copper holding grid. The results show the formation of Ag atoms at $2.7 \mathrm{keV}$, thus EDX confirmed the formation of AgNPs [28-30]. The presence of oxygen could be due to oxygen species in flavonoids [29].

\subsection{Toxicity of LTP-AgNPs on Fungi}

LTP-AgNPs were screened to evaluate its toxicity effects on P. italicum. Two sets of LTP-AgNPs were used: suspended LTP-AgNPs and precipitated LTP-AgNPs. LTP-AgNPs were tested at $5 \mu \mathrm{M}$ concentrations on P. italicum, and the results exhibited no difference between both the suspended and the precipitated LTP-AgNPs. The growth of fungi spores on agar plates with the treatment of suspended LTP-AgNPs are shown in Figure 3a.

Table 1 shows the average diameter $(\mathrm{mm})$ measurement representing the zone of inhibition for spores in each plate. The control in Figure 1a shows the greatest diameter since it did not receive the treatment of any LTP-AgNPs. The decrease in diameters of spores in each plates (v), (vi), (vii), (viii) after the treatment of various LTP-AgNPs was significant. Furthermore, none of the AgNPs showed $100 \%$ suppression of P. italicum growth at $1 \mu \mathrm{M}$ concentration, while LTP-AgNP1 and LTP-AgNP5 suppressed the growth completely (Figure 1a). LTP-AgNP4 did not show any toxic effect at up to $50 \mu \mathrm{M}$ at which concentration suppression was not significant. LTP-AgNP2, LTP-AgNP3, LTP-AgNP-6, LTP-AgNP7 prevented the growth of mycelia as depicted in Figure 3a (v), (vi), (vii), and (viii), respectively. 

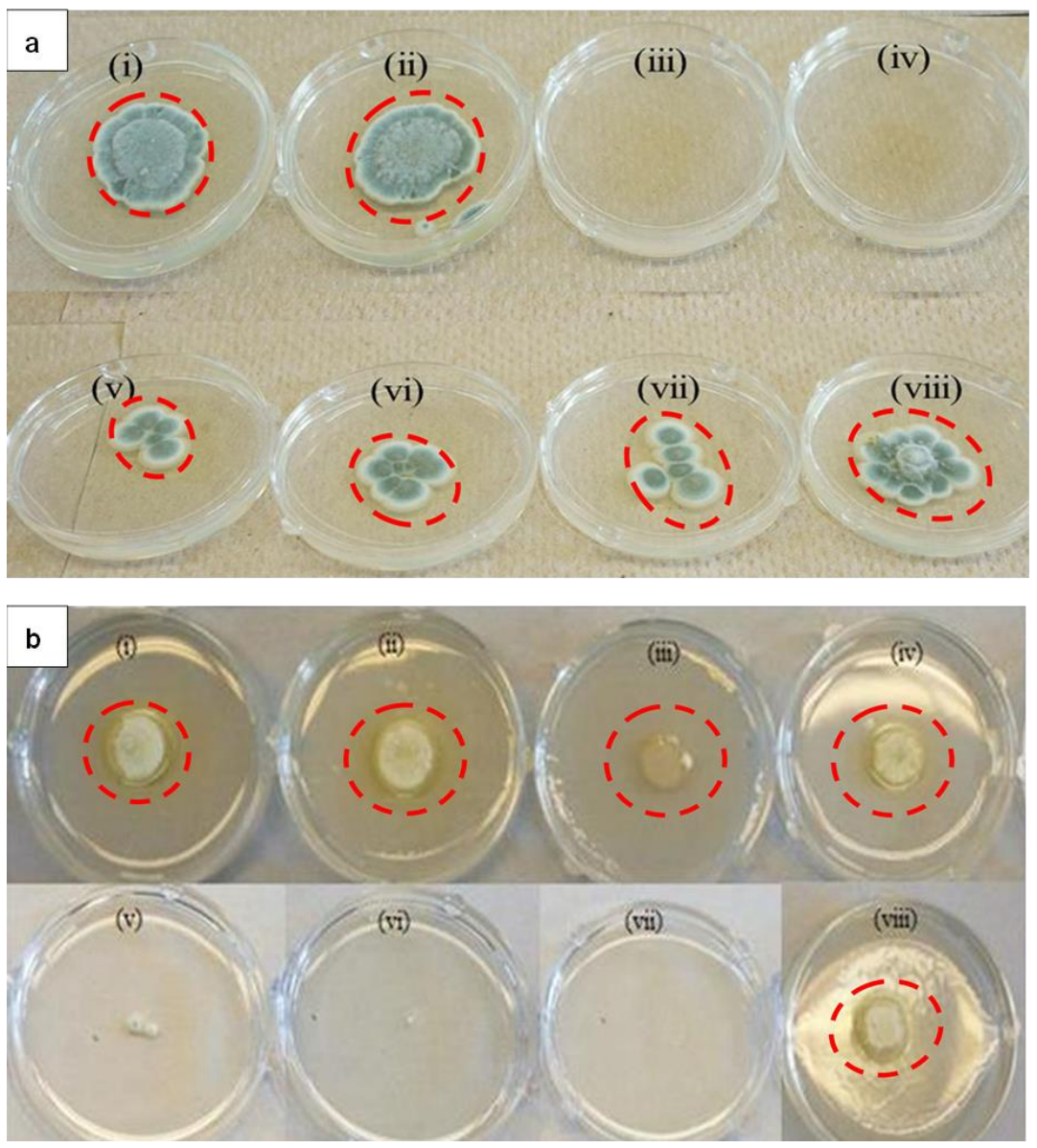

Figure 3. (a) Toxicity of $5 \mu \mathrm{M}$ LTP-AgNPs on $10^{3}$ spores/mL P. italicum (i) control, (ii) LTP-AgNP4, (iii) LTP-AgNP1 (iv) LTP-AgNP5, (v) LTP-AgNP2, (vi) LTP-AgNP3, (vii) LTP-AgNP6 and (viii) LTP-AgNP7. LTP-AgNPs were filtered through $0.2 \mu \mathrm{m}$ filter. LTP-AgNPs at 1, 5, 10 and $50 \mu \mathrm{L}$ of the $5 \mu \mathrm{M}$ concentrations were added to dextrose-tryptone broth media containing $10^{3} \mathrm{spores} / \mathrm{mL}$ P. italicum, which were incubated at $25^{\circ} \mathrm{C}$ incubator for two-days. Then, $100 \mu \mathrm{L}$ from each medium were transferred onto freshly prepared PDA agar, which were incubated 4-days at $25{ }^{\circ} \mathrm{C}$ incubator. (b) Toxicity of $5 \mu \mathrm{M}$ LTP-AgNPs on P. italicum on PDA agar for 2 days incubation. LTP-AgNPs were filtered through $0.2 \mu \mathrm{m}$ filter. $10^{3}$ spores in $100 \mu \mathrm{L}$ were placed on the center of the plate, where $50 \mu \mathrm{L}$ of the NPs were placed around the inoculum for (i), (ii), (iii) and (iv) for LTP-AgNP5, LTP-AgNP3, LTP-AgNP2 and LTP-AgNP7, respectively. While the NPs introduced to PDA agar right after the autoclave process (v), (vi), (vii) and (viii) for LTP-AgNP5, LTP-AgNP2, LTP-AgNP1 and LTP-AgNP7, respectively.

Table 1. Average diameter measurement of spores showing effects of LTP-AgNPs on the growth of P. italicum.

\begin{tabular}{ccc}
\hline Types of NP & Day $\mathbf{2}(\mathbf{m m})$ & Day $\mathbf{4}(\mathbf{m m})$ \\
\hline Control & 12.5 & 18 \\
LTP-AgNP1 & 0 & 0 \\
LTP-AgNP2 & 8 & 13 \\
LTP-AgNP3 & 9 & 14 \\
LTP-AgNP4 & 12 & 17 \\
LTP-AgNP5 & 0 & 0 \\
LTP-AgNP6 & 7 & 12 \\
LTP-AgNP7 & 11 & 15 \\
\hline
\end{tabular}


Figure $3 b$ shows that the applied LTP-AgNPs did not make direct contact with the P. italicum. As a result, no significant toxicity was recognizable. However, the applied stress prevented the formation of a blue-green microscopic view of P. italicum for all of the tested LTP-AgNPs. In contrast to this, when LTP-AgNP5, LTP-AgNP2, and LTP-NP1 were evenly spread in PDA agar, dramatic suppression of $P$. italicum growth was observed. LTP-AgNP2 showed better anti-P. italicum capability on agar, which is unusual from Figure $3 \mathrm{~b}$ (vi). In addition, the zone of inhibition measured was $10 \mathrm{~mm}$, which was the same for the spores.

Similar to P. italicum, C. gloeosporioides showed maximum vulnerability towards LTP-AgNP5 and LTP-AgNP1 (Figure 4a (ii)). LTP-AgNP4 (Figure 4a (iv)) and LTP-AgNP6 (Figure 4a (vii)) showed minimal effect while Figure 4a (v), (vi), and (viii) for LTP-AgNP2, LTP-AgNP3, LTP-AgNP7, respectively, showed no recognizable effect. Although LTP-AgNP2 showed recognizable toxicity towards P. italicum, it did not show any recognizable toxicity towards C. gloeosporioides. Silver nanoparticles, due to their strong anti-C. gloeosporioides capability, were offered as an alternative to fungicides [31]. The LTP-AgNP1 and AgNP5 provided stronger anti-C. gloeosporioides activity in comparison to the reported ones [31]. The diameter of the spores measured as $15 \mathrm{~mm}$ representing the zone of inhibition appeared to be similar for all the plates.
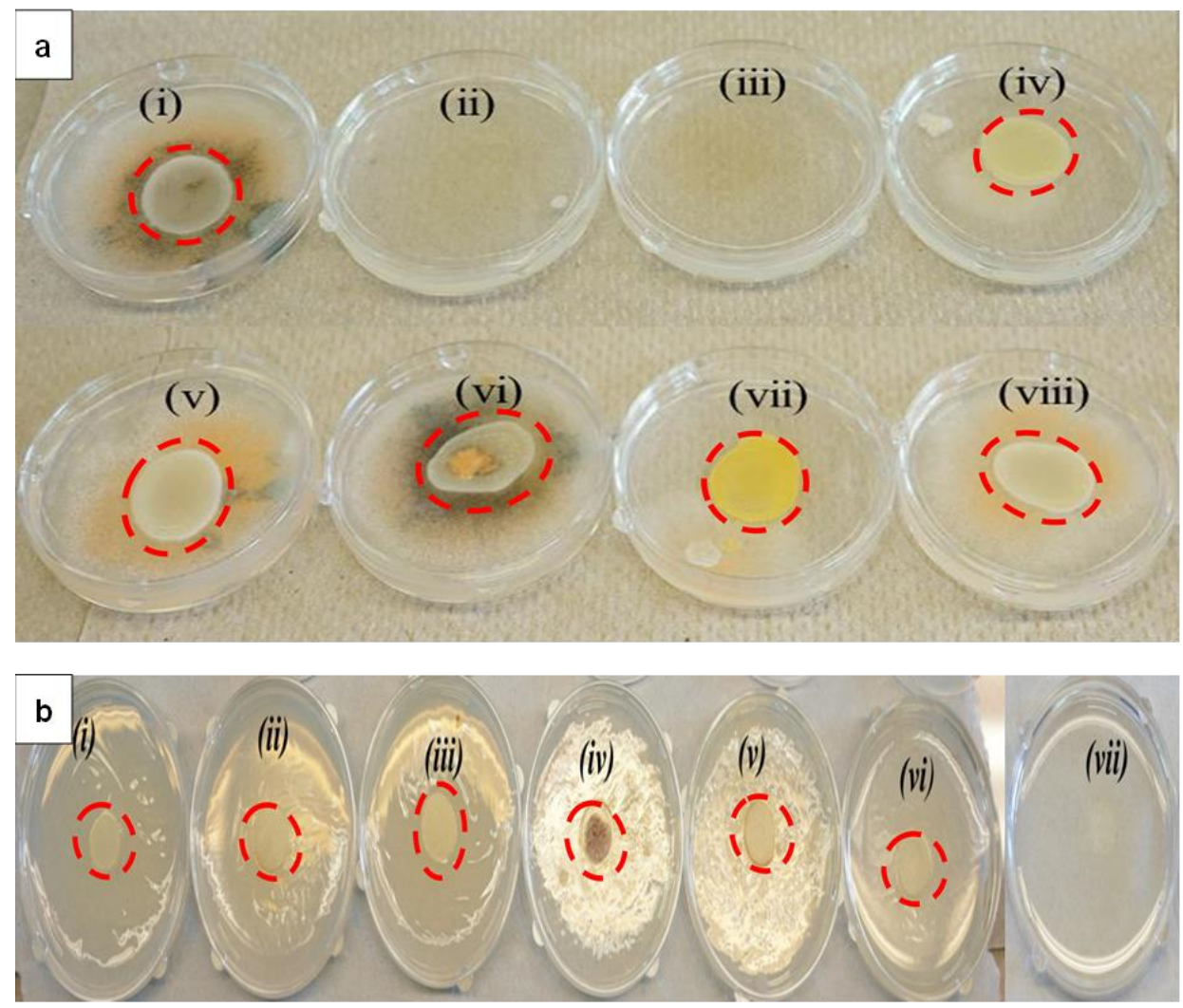

Figure 4. (a) Toxicity of $5 \mu \mathrm{M}$ LTP-AgNPs on $10^{3}$ spores/mL C.gloeosporioides (i) Control, (ii) LTP-AgNP5, (iii) LTP-AgNP1, (iv) LTP-AgNP4, (v) LTP-AgNP2, (vi) LTP-AgNP3, (vii) LTP-AgNP6 and (viii) LTP-AgNP7. LTP-AgNPs were filtered through $0.2 \mu \mathrm{m}$ filter. LTP-AgNPs were applied at $1-50 \mu \mathrm{M}$ to $10^{3}$ spores/mL C. gloeosporioides in dextrose-tryptone broth for 2 days. Then, $100 \mu \mathrm{L}$ from each medium were transferred onto freshly prepared PDA agar, which were incubated 4-days at $25{ }^{\circ} \mathrm{C}$ incubator. (b) Toxicity of $5 \mu \mathrm{M}$ LTP-AgNPs on T. biforme on PDA agar at 2-day incubation. LTP-AgNPs were filtered through $0.2 \mu \mathrm{m}$ filter. $10^{3}$ spores in $100 \mu \mathrm{L}$ were placed on the center of the plate, where the NPs introduced to PDA agar right after the autoclave process (i) T. biforme control, (ii) LTP-AgNP5, (iii) LTP-AgNP3, (iv) LTP-AgNP7, (v) LTP-AgNP6, (vi) LTP-AgNP1, and (vii) LTP-AgNP2. 
In contrast to P. italicum and C. gloeosporioides, T. biforme showed its maximum vulnerability towards LTP-AgNP2 (Figure 4 (vii)), followed by LTP-AgNP1 (Figure 4 (vi)).It is worth noting that T. biforme is a white-rotten mushroom, and this was the main difference of T. biforme from P. italicum and C. gloeosporioides. Interestingly, LTP-AgNP7 (Figure 4 (iv)) formed a shiny layer on the agar, which was not observed for P. italicum and C. gloeosporioides, and this could be attributed to the antimicrobial effect of the LTP-AgNP7. Finally, the diameter of spores in each plate was approximately $5 \mathrm{~mm}$, the zone of inhibition was not significant.

LTP-AgNP1 and LTP-AgNP5 were compared to the LT for their toxicities on A. nidulans (Figure 5 and Figure S2). At the tested concentrations, LTP-AgNP1 and LTP-AgNP5 showed complete suppression of $A$. nidulans while LT did not eliminate the growth even at $280 \mu \mathrm{M}$ level (Figure 5).

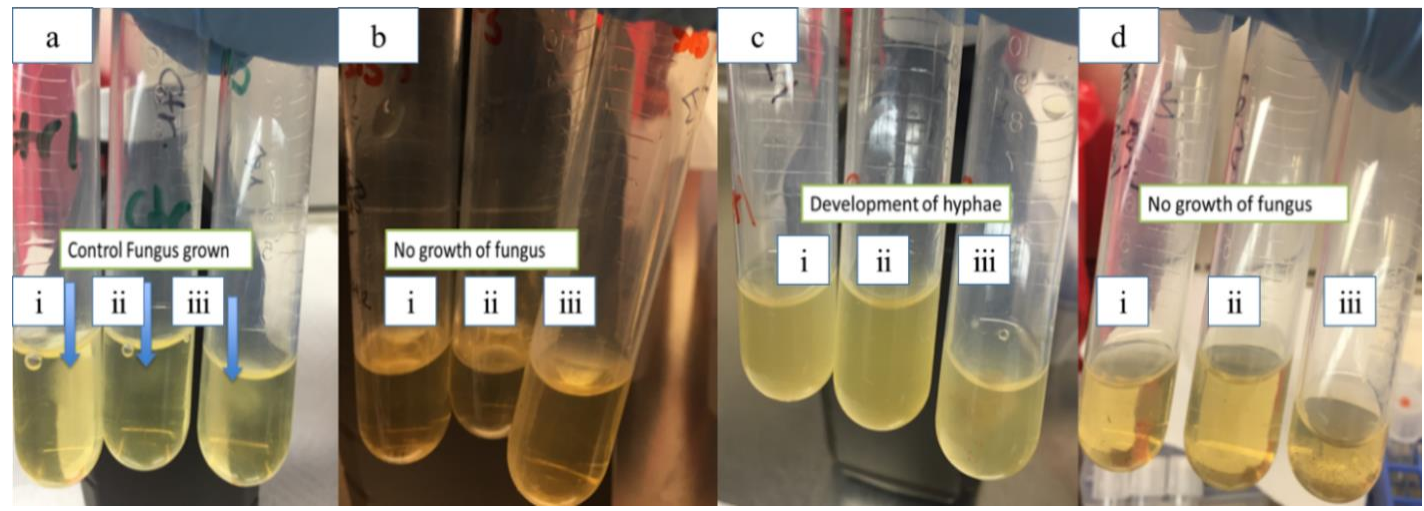

Figure 5. Turbidity study using A. nidulans: (a) Control of $A$. nidulans, (b) (i) $1 \mu \mathrm{M}$, (ii) $2 \mu \mathrm{M}$ and (iii) $4 \mu \mathrm{M}$ LTP-AgNP1, (c) (i) $70 \mu \mathrm{M}$, (ii) $140 \mu \mathrm{M}$ and (iii) $280 \mu \mathrm{M}$ LT, (d) (i) $10 \mu \mathrm{M}$, (ii) $72 \mu \mathrm{M}$ and (iii) $144 \mu \mathrm{M}$ LTP-AgNP5; $24 \mathrm{~h}$ incubation.

When the incubation time was increased to $72 \mathrm{~h}$, the growth of $A$. nidulans at $4 \mu \mathrm{M}$ concentrations was observed. At $10 \mu \mathrm{M}$ concentration, LTP-AgNP1, LTP-AgN2, and LTP-AgNP5 completely suppressed the growth (Figure 6).

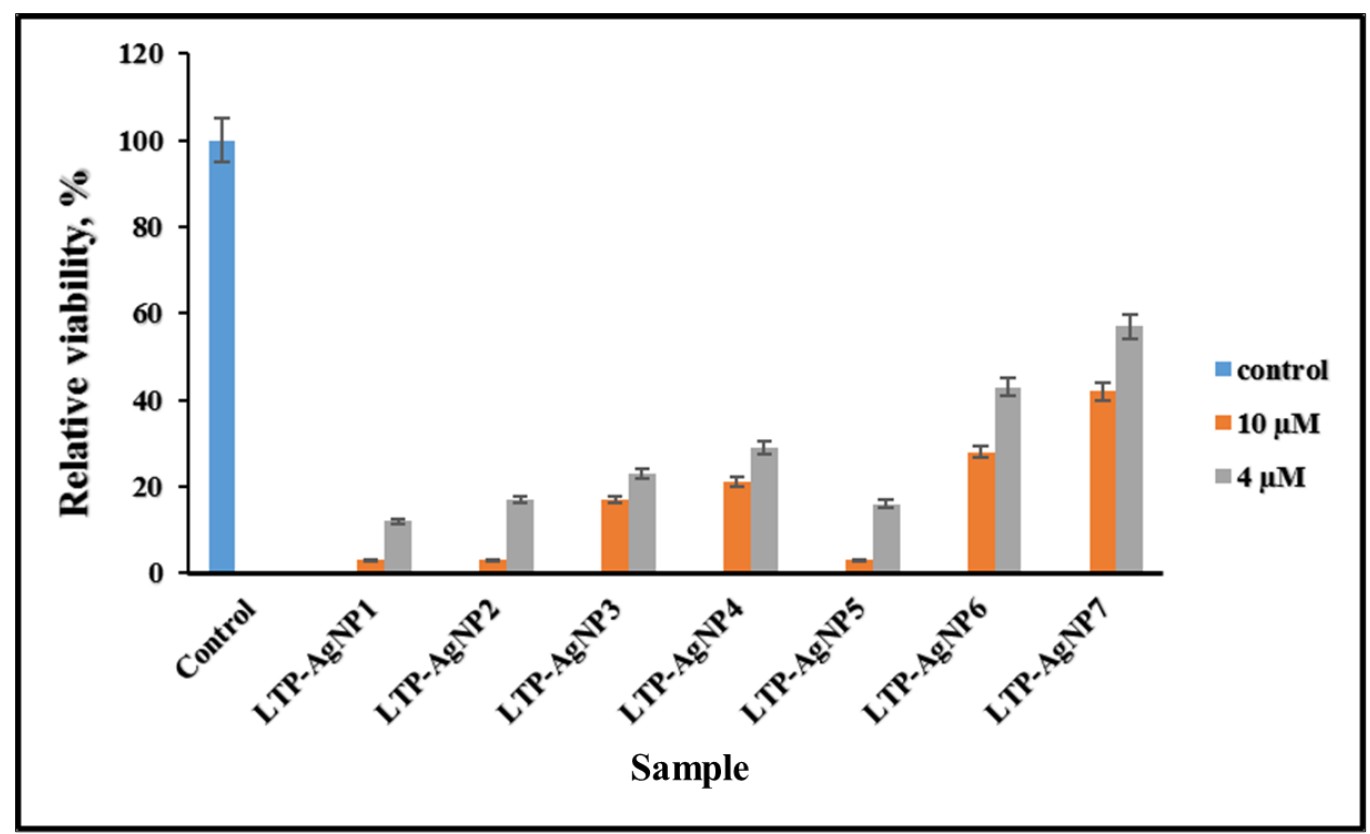

Figure 6. Toxicity of LTP-AgNPs on $10^{3}$ spores/mL A. nidulans in dextrose tryptone broth, incubated for 3 days at $25^{\circ} \mathrm{C}$. 


\subsection{Toxicity of LTP-AgNPs on Bacteria}

LTP-AgNPs showed toxicity towards all the tested bacterial cultures (Figure 7a-c; Figure 8a-c; Figures S3 and S4). The vulnerability of the bacteria towards the LTP-AgNPs did not show dependence on the used LTP-AgNPs; instead, the vulnerability was dependent on the concentration of the AgNPs. Among the tested LTP-AgNPs, only LTP-AgNP1 and LTP-AgNP5 showed complete suppression of the growth at the tested highest levels, $15 \mu \mathrm{M}$.
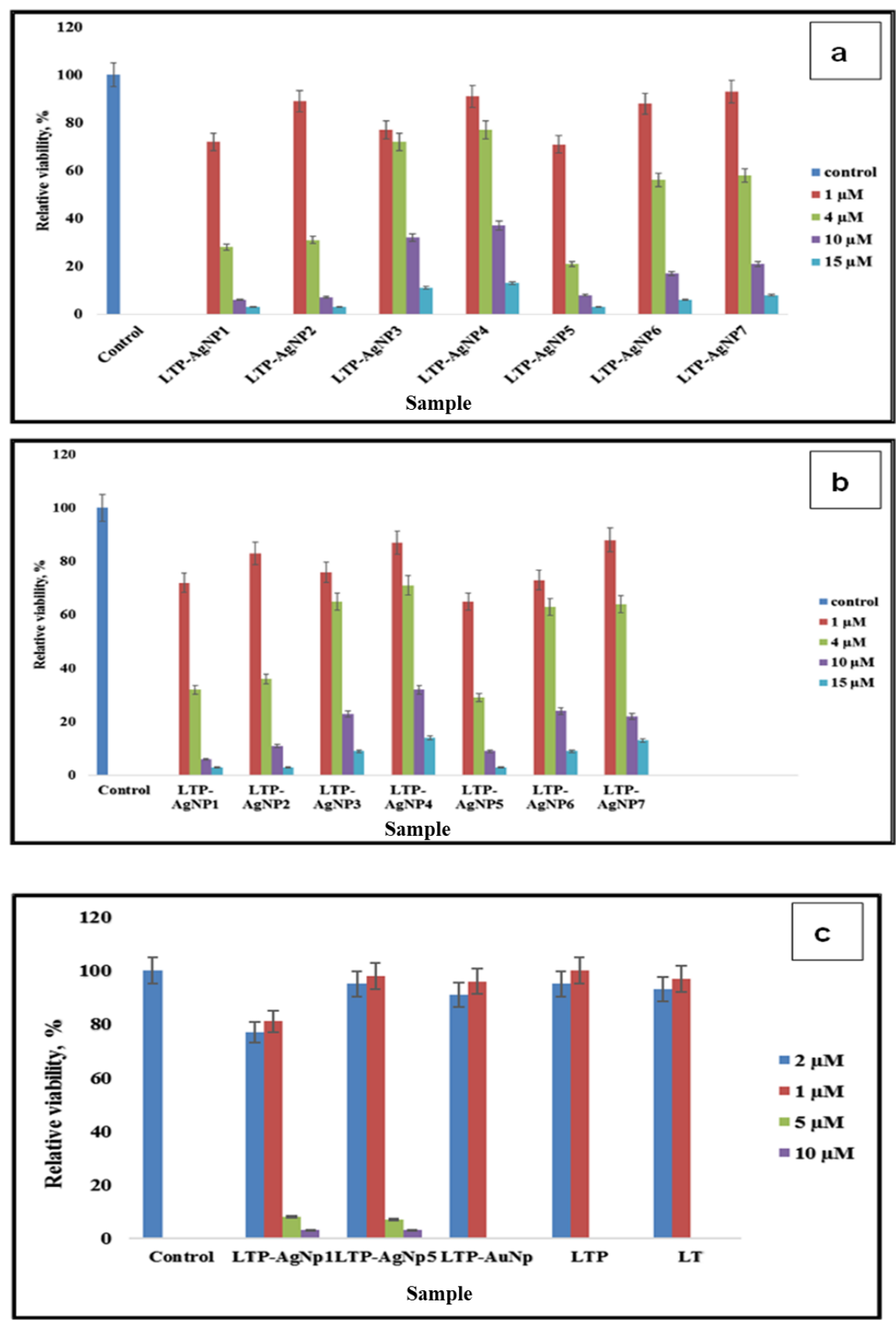

Figure 7. (a) Toxicity of LTP-AgNPs on $10^{4} \mathrm{cfu} / \mathrm{mL}$ Staphylococcus epidermidis in nutrient broth. At $15 \mu \mathrm{M}$, the absorbance of LTP-AgNP1 and LTP-AgNP5 did not give a higher value than the initially measured one, so to make it visible, relative viability was assigned as 3. (b) Toxicity of LTP-AgNPs on $10^{4} \mathrm{cfu} / \mathrm{mL}$ Citrobacter freundii in nutrient broth. At $15 \mu \mathrm{M}$, the absorbance of LTP-AgNP1 and LTP-AgNP5 did not give a higher value than the initially measured one, so to make it visible, relative viability was assigned as 3. (c) Toxicity of LTP-NPs on $10^{4} \mathrm{cfu} / \mathrm{mL}$ Escherichia coli in nutrient broth. 

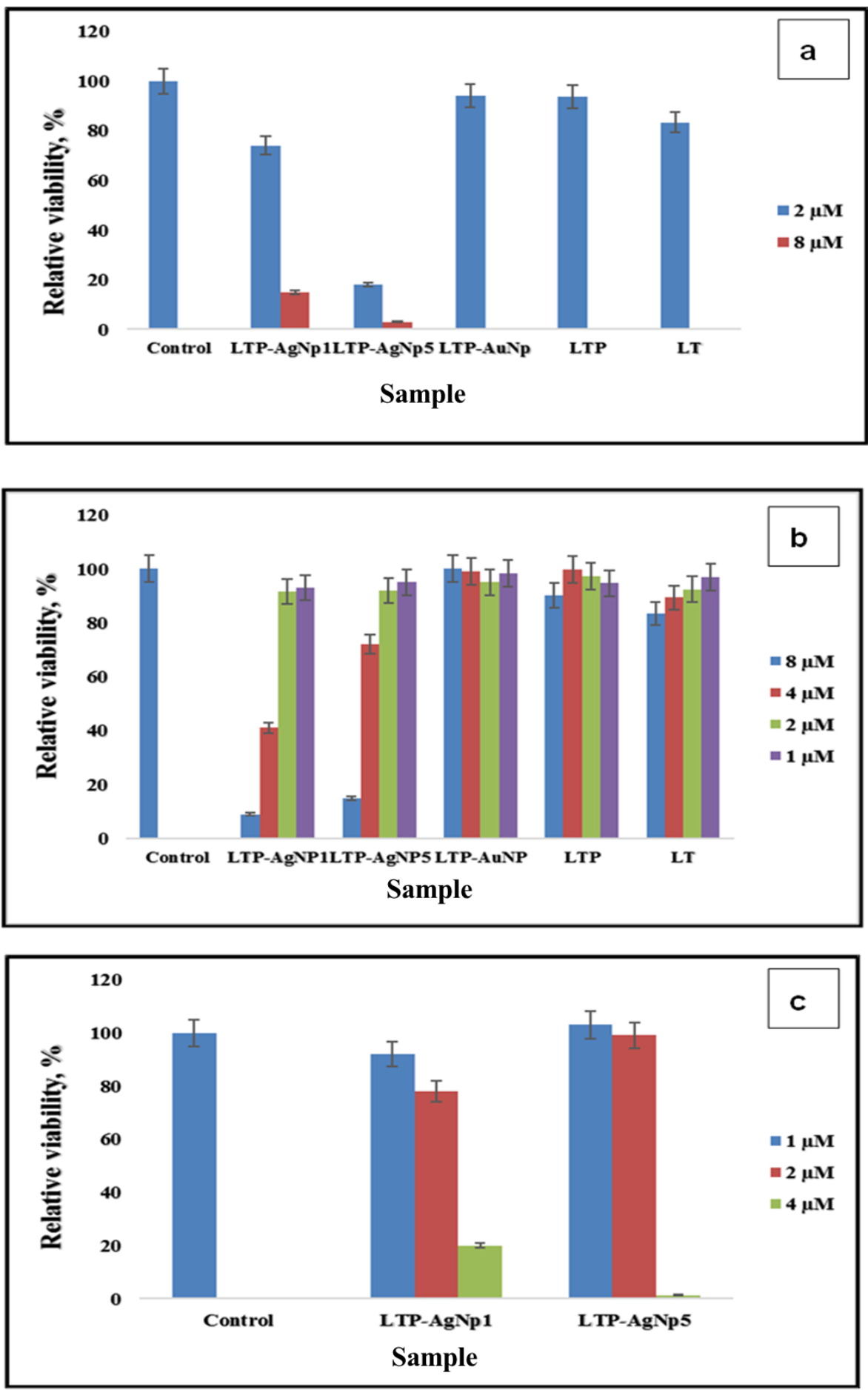

Figure 8. (a) Toxicity of LTP-NPs, LTP, LT on $10^{4} \mathrm{cfu} / \mathrm{mL}$ Aeromonas hydrophilia in lysogeny broth. (b) Toxicity of LTP-NPs, LTP, LT on $10^{4} \mathrm{cfu} / \mathrm{mL}$ Pseudomonas aeruginosa in lysogeny broth. (c) Toxicity of LTP-AgNPs on $10^{4} \mathrm{cfu} / \mathrm{mL}$ Listeria monocytogenes in lysogeny broth.

Similar to antifungal capability, LT, LTP, and LTP-AuNPs did not show strong antibacterial capability, while corresponding LTP-AgNPs showed promising antibacterial ability.

To investigate the inhibitory effects of LTP-AgNPs on the growth of bacterial culture, we treated E. coli with $10 \mu \mathrm{m}$ LTP-AgNP1 for the initial reaction. We treated the next E. coli culture with $10 \mu \mathrm{m}$ LTP-AgNP5, and the optical density at $595 \mathrm{~nm}\left(\mathrm{OD}_{595}\right)$ of the resulting bacterial cultures was measured 
at $1 \mathrm{~h}$ time intervals. Figure 9 shows the measurements of OD at $595 \mathrm{~nm}$ taken over an hourly time interval for $25 \mathrm{~h}$.

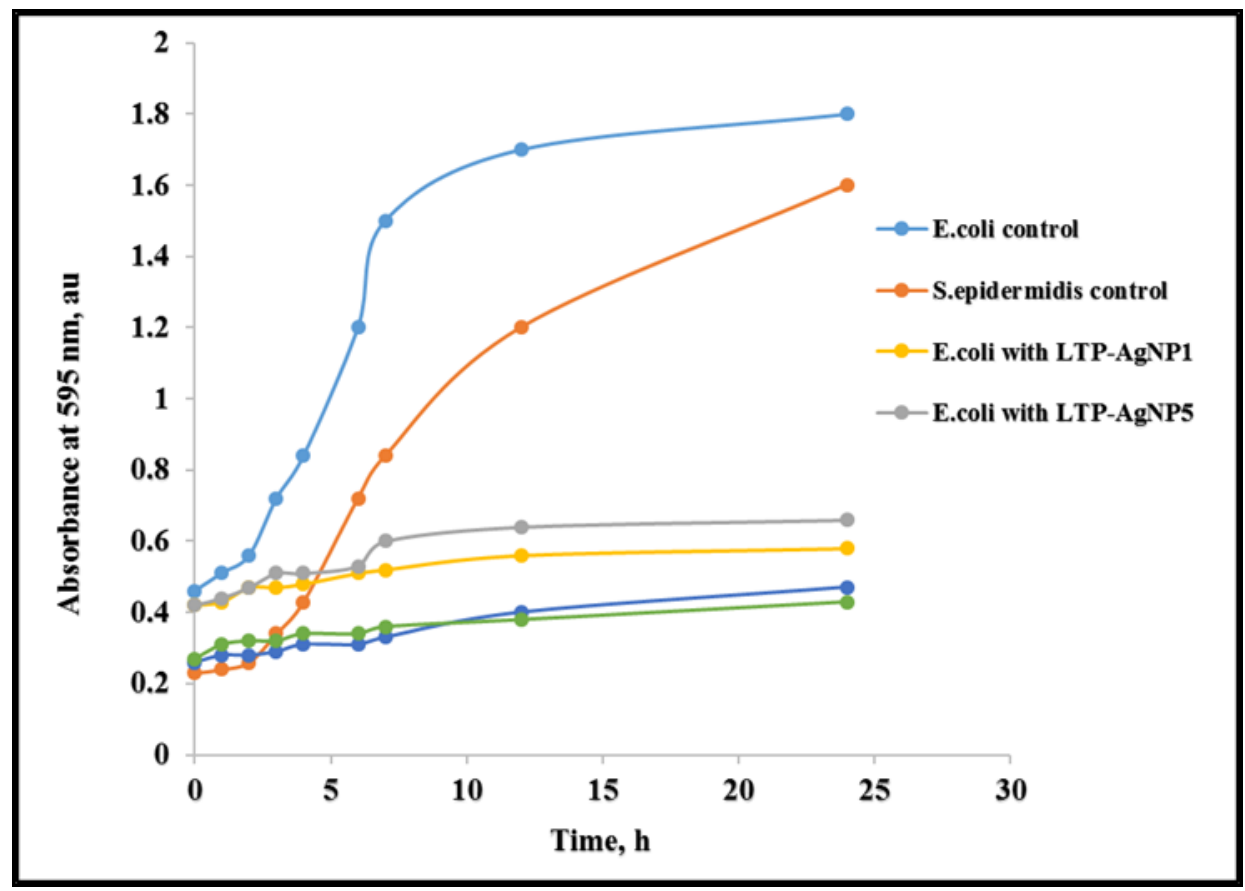

Figure 9. Effect of $10 \mu \mathrm{M}$ LTP-AgNP1 and $10 \mu \mathrm{M}$ LTP-AgNP5 on the growth kinetics of E. coli and S. epidermidis in Mueller-Hinton Broth.

The $\mathrm{OD}_{595}$ values were as follows: 0.43 for E. coli (control), 0.24 for S. epidermidis (control). After the initial $4 \mathrm{~h}$ growth mark, the $\mathrm{OD}_{595}$ for E. coli when treated with LTP-AgNP1 and LTP-AgNP5 were approximately 0.42 , while the OD for the control was around 0.9 a.u. We observed that the control set-up grew exponentially between 9-10 h, while the growth rate of treated bacterial culture plateaued around $10 \mathrm{~h}$. This pronounced difference was expected since $10 \mu \mathrm{m}$ LTP-AgNP1 and $10 \mu \mathrm{m}$ LTP-AgNP5 inhibited the growth of the bacterial culture.

Furthermore, to explain how the LTP-AgNPs showed their antibacterial capability, growth kinetics of E. coli and S. epidermidis underexposure of LTP-AgNP1 and LTP-AgNP5 were tested. Under no stress conditions, both E. coli and S. epidermidis entered the log phase, where their growth was exponential. On the contrary, both E. coli and S. epidermidis could not surpass the stress introduced by the AgNPs to boost-up their growth. Therefore, it can be speculated that the lethal dose of LTP-AgNPs confined to the tested bacteria into lag-phase, where no actual overall growth can be claimed. This is a common observation for the toxic levels of AgNPs [13,32]. Furthermore, the dissolution of LTP-AgNPs silver releases antimicrobial silver ions that interact with thiol functional groups contained in the proteins embedded in the cell wall. This alters the structural function and the growth of the bacteria. This is the proposed mechanism underlying the antimicrobial activity for silver nanoparticles [33].

\subsection{Cytotoxicity of LTP-AgNPS}

The Caco2 cell line originates from human colon carcinoma. It serves as a model that mimics the in vivo system by exhibiting specialized enterocytes function via biochemical activities as the result of the enzymes located in the small intestines [34]. They are heterogeneous and possess an ability to differentiate spontaneously to express different morphologies and functions, which are features of matured enterocytes [35]. HUVEC cells are models obtained from the endothelium of veins located in the umbilical cord. Caco-2 cells and HUVEC cells are both primary epithelial cell lines. The NPs exposure was $24 \mathrm{~h}$ since, for the first $\sim 10 \mathrm{~h}$, the toxicity might not be clearly seen [36], which could 
provide biased results. All the LTP-AgNPs showed toxicity towards the cell lines non-selectively. Since HUVEC cells are more delicate, they showed higher vulnerability, which was concentration-dependent. It should be noted that the tested concentrations (i.e., 25 and $50 \mu \mathrm{M}$ ) completely suppressed the growth of the tested cell lines. However, the least viable cell line (HUVEC $50 \mathrm{uM}$ ) was approximately $60 \%$ (Figure 10).

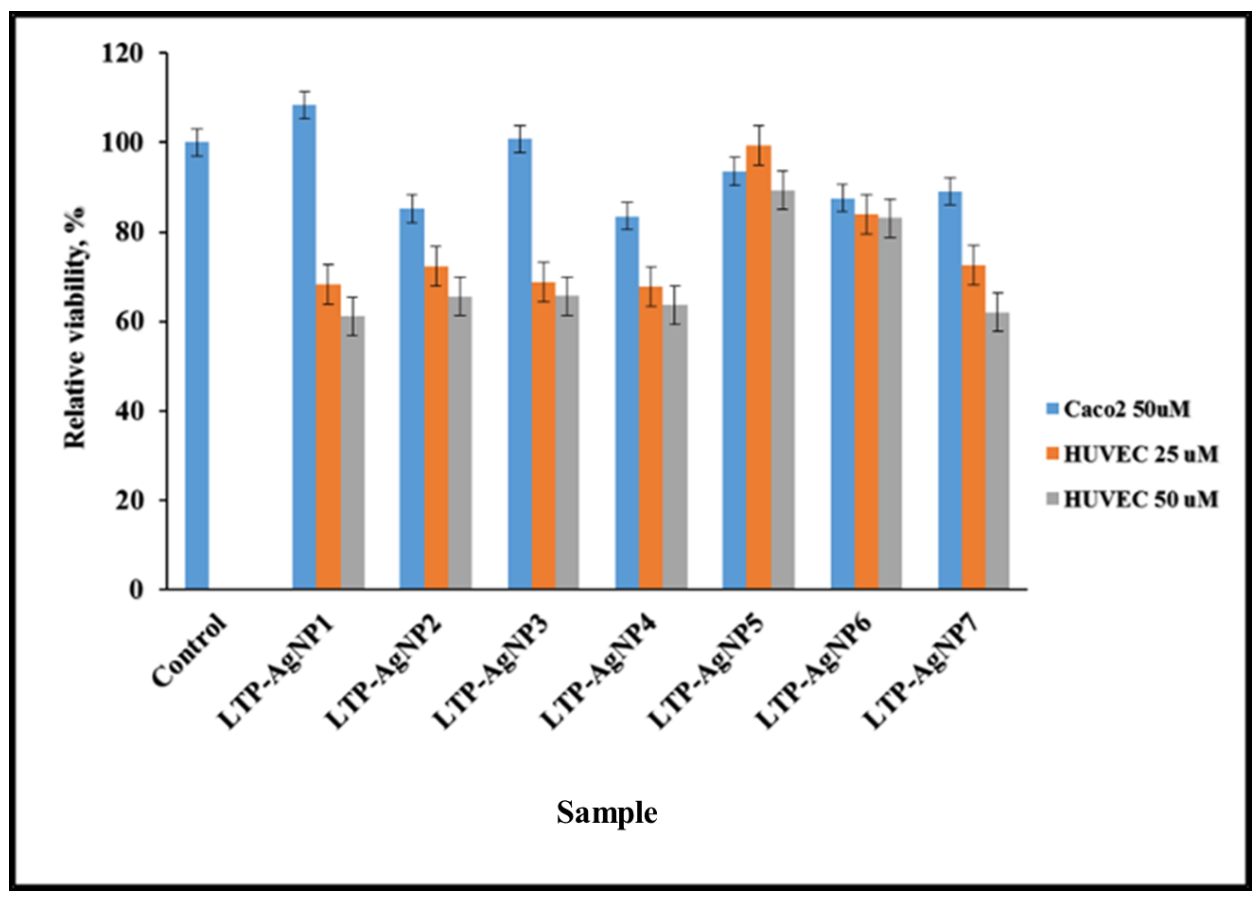

Figure 10. Cytotoxicity of LTP-AgNPs on Caco-2 and HUVEC cells.

\section{Discussion}

The tested LTP-AgNPs showed promising antimicrobial capabilities against both the tested fungi and bacteria, while their cytotoxic effects were relatively limited. The antifungal capacity of the tested AgNPs was higher in comparison to those obtained against the tested bacteria. However, in all cases, the size and shape of the LTP-AgNPs brought the antimicrobial capability. In contrast to this, LTP-AuNPs and LTP and LT compounds did not show any comparable antimicrobial activity in comparison to LTP-AgNPs.

Here, it can be speculated that silver nanoparticles generate silver ions during incubation while gold nanoparticles were more strictly stabilized by LTP with a limited release of ions into the media. AgNPs enter the cell via receptor-mediated endocytosis. Following a cascade pathway, the silver nanoparticles initially end up in the endosome and then continue to the lysosome. AgNPs faces a varying acidic environment of $\mathrm{pH} 4$ to $\mathrm{pH}$. Liu has reported that at lower $\mathrm{pH}$, there is an increase in the ion release while investigating the dissolution of silver nanoparticles at different $\mathrm{pH}$ [37].

In that respect, smaller size AgNPs exhibited greater antimicrobial activity compared to the larger ones. The smaller size AgNPs accumulates easily and has a greater effect on the target organelle in comparison to the larger size nanoparticles [38]. Studies have shown that the size of AgNPs plays a significant role in membrane disruption of microbes and hence affects the bacteria viability [33,39-44].

The antifungal activities of silver nanoparticles have been reported for a variety of fungi such as humans [44,45], plants [46], and household pathogens [47]. Therefore, mechanistic studies have been conducted here to further understand the activity of AgNPs towards fungi. AgNPs can enter the fungi by damaging cell membranes and cell surface, which then disrupts organelles such as the energy center (mitochondria) and essential units of protein synthesis (ribosomes) [48]. In the case of small-sized nanoparticles, the possibility of this event could be significant because these would not 
require any significant disruption of the cellular membrane. Therefore, we believe that the small-sized spherical nature of LTP-AgNP1 enhanced antimicrobial capability. In agreement with prior work, this observation could be attributed to the available area-per-volume that interacts with the cellular membrane of A. nidulans [44].

The results clearly depict that at $5 \mu \mathrm{M}$ concentrations, LTP-AgNP1 (9 nm spherical) and LTP-AgNP5 (quasi-spherical $21 \mathrm{~nm}$ ) showed $100 \%$ suppression of growth of P. italicum (Figure 3) and C. gloeosporioides (Figure 4a) for the tested 4-day incubation period. LTP-AgNP6 (37 nm quasi-spherical) inhibited 60\% growth of P. italicum (Figure 3) and 70\% mycelial growth of C. gleoesporoides (Figure 4a) with altering the macroscopic view. Although LTP-AgNP2 and LTP-AgNP3 inhibited $~ 50 \%$ growth of P. italicum, they did not show any effect on C. gloeosporioides. The same trend was observed for A. nidulans; LTP-AgNP1, LTP-AgNP2, and LTP-AgNP5 showed a similar capability to inhibit growth while LTP-AgNP7 showed nearly no effect (Figure 6). However, LTP-AgNP7 (21 nm spherical) did not show any strong impact on both P. italicum and C. gloeosporioides, while it was observed the only AgNP inhibited the growth of T. biforme. Pal et al. (2007) reported the shape is critical in revealing the toxicity of the AgNPs [13]; the quasi-spherical AgNPs with their truncated nature might have found strong interaction capability with the fungal cells. These two plant pathogens are among the most common post-harvest disease triggering fungi, so the outstanding antifungal ability of the AgNPs can make them attractive as an alternative to fungicides.

The tested LTP-AgNPs showed a unique impact on mycelial growth of P. italicum, which was not observed for the rest of the fungi. As seen from Figure 3a, LTP-AgNP2, LTP-AgNP3, LTP-AgNP6, and LTP-AgNP7 prevented one unit-body mycelial formation. This could be related to the fact that LTP-AgNPs blocked the continuous growth of mycelia through distorting the hyphae wall [31], the cell surfaces, and interfering with the signaling cascades [49]. P. italicum was shown to be capable of synthesizing AgNPs [50] as well, which could also be one of the possibilities of the altered response of P. italicum to the LTP-AgNPs.

Previous studies have shown that AgNPs derived from phosphorylated flavonoids exhibited excellent antibacterial activity $[25,51]$. In addition to size, the shape also showed the importance of similar-sized LTP-AgNPs, where quasi-spherical LTP-AgNPs showed higher capability (LTP-AgNP5) than corresponding similar-sized spherical ones. The presented concentrations for antifungal and antibacterial are only the ones in which one of the tested LTP-AgNPs gave $100 \%$ suppression for the tested fungi and bacteria. Therefore, $4-10 \mu \mathrm{M}$ for antifungal tests and 2-15 $\mu \mathrm{M}$ for antibacterial tests are the accepted highest concentrations to be presented in the study.

The antibacterial capability of LTP-AgNPs showed a similar trend observed for the tested fungi. LTP-AgNP1 and LTP-AgNP5 showed the best antibacterial activities towards the tested bacterial species, for which $4-15 \mu \mathrm{M}$ concentrations range were observed as the minimal concentration to inhibit $100 \%$ growth. In contrast to the fungi, size effect was more evident for the antibacterial capability; LTP-AgNP2 (16 nm spherical) showed unique antibacterial capability, which was not seen observed as an excellent antifungal agent. Similarly, at $15 \mu \mathrm{M}$, the rest of the LTP-AgNPs eliminated over $70 \%$ of $C$. freundii and S. epidermidis. The observed results for A. hydrophilia, P. aeruginosa, E. coli, and L. monocytogenes were slightly different than C. freundii and S. epidermidis for the lowest concentration to inhibit over $99.99 \%$ growth (Figures $7 \mathrm{a}-\mathrm{c}$ and $8 \mathrm{a}-\mathrm{c}$ ). Furthermore, at $8 \mu \mathrm{M}$ LTP-AgNP1 only eliminated $\sim 70 \%$ of the growth, which did not follow the commonly observed trend for the tested microorganisms. A. hydrophilia, $P$. aeruginosa, and L. monocytogenes are pathogenic bacteria, which require intensive antibiotic treatment because of their antibiotic-resistant natures. The developed AgNPs showed very high toxicity towards them, which can open a new window for these relatively benign AgNPs to be used as antibiotics.

LTP-AgNP5 (21 nm quasi-spherical) showed similar capability to LTP-AgNP1 (9 nm spherical) and higher potential than LTP-AgNP2 (16 nm spherical). For similar-sized LTP-AgNPs, shape brought dramatic effect, where LTP-AgNP2, in general, required at least two-times concentration of LTP-AgNP5 to show the same effect on tested fungi and bacteria. However, interestingly LTP-AgNP7 (21 nm spherical) did not show any descent antimicrobial activity except towards T. biforme. This is a 
dramatic observation that shifting from quasi-spherical to spherical at $21 \mathrm{~nm}$ size; the antimicrobial capability was not observable the presented concentrations. The antifungal capability of the tested LTP-AgNPs obtained was higher in comparison to those obtained against the tested bacteria. Although the antimicrobial activity of LTP-AgNPs and LTP-AuNPs were effective at sizes below $100 \mathrm{~nm}$, the cubic shaped LTP-AuNPs at sizes 372 and $510 \mathrm{~nm}$ did not exhibit any antimicrobial activity. This is in agreement with previous studies which demonstrated that smaller nanoparticle sizes exhibited significant antimicrobial activity.

Future work will focus on the treatment of wastewater by AgNPs to destroy resistant bacteria.

\section{Materials and Methods}

\subsection{Synthesis and Physicochemical Characterization of Gold and Silver Nanoparticles}

The synthesis of LTP followed the procedure described in our previous work [19,52] with slight modification in the use of equivalents of Dibenzyl phosphite (Sigma-Aldrich, St. Louis, MO) in phosphorylation of Luteolin (Indofine Chemicals inc., Hillsborough, NJ). Flash chromatography Combiflash companion/TS Model serial 207L20329, Teledyne Isco, Inc., was used for the purification of the products. ${ }^{1} \mathrm{H}$, ${ }^{13} \mathrm{C},{ }^{31} \mathrm{P}$ NMR spectra were obtained using $600 \mathrm{MHz}$ (Bruker Avance). The TLC analyses were performed using $0.25 \mathrm{~mm}$ EM Silica Gel 60 F250 plates visualized by UV irradiation ( $254 \mathrm{~nm}$ ).

Synthesis and physicochemical characterization of AgNPs and AuNPs were already described as reported in our previous work [19]. Typically, in this study, AgNPs and AuNPs were synthesized by using Luteolin tetraphosphate (LTP) as the reducing and stabilizing agent, as reported in our previous work [15]. Briefly, AuNPs were synthesized by reacting $300 \mu \mathrm{L}$ of $5 \mathrm{mM}$ gold (III) chloride $\left(\mathrm{HAuCl}_{4} \cdot 3 \mathrm{H}_{2} \mathrm{O}\right.$, Sigma-Aldrich, Milwaukee, WI) with different concentrations of $5 \mathrm{mM}$ LTP whereby $200,300,400,600$, and $800 \mu \mathrm{L}$ LTP for the formation of spherical and quasi-spherical nanoparticles. The second set was done by varying the concentration of $\mathrm{HAuCl}_{4} \cdot 3 \mathrm{H}_{2} \mathrm{O}$ whereby $100,200,300,400$, and $500 \mu \mathrm{L}$ of $5 \mathrm{mM} \mathrm{HAuCl} 4 \cdot 3 \mathrm{H}_{2} \mathrm{O}$ were each reacted for $90 \mathrm{~min}$ with $600 \mu \mathrm{L}$ of $5 \mathrm{mM}$ LTP for the formation of gold nanocubes. The AuNPs were washed three times using nanopure water. In this synthesis, $4.5 \mathrm{mM}$ of silver nitrate $\left(\mathrm{AgNO}_{3}, 99 \%\right.$, Sigma-Aldrich, Milwaukee, WI $)$ was reacted with different concentrations of L.T.P. AgNPs were synthesized by varying the concentration of $5 \mathrm{mM}$ $\mathrm{AgNO}_{3}: 5 \mathrm{mM}$ LTP in the ratio of 1:1, 1:2, 1:3, 2:1.5, and 2:3. The reaction was carried out at room temperature and monitored using UV-Vis for about $300 \mathrm{~min}$. The AuNPs and AgNPs solutions formed were sonicated for $30 \mathrm{~min}$ in an ultrasound bath and were then centrifuged $3500 \mathrm{rpm}$ for $30 \mathrm{~min}$ to obtain pellets, which were then washed three times using $18 \mathrm{M} \Omega \mathrm{cm}$ nanopure water. UV/Vis absorption spectra were carried out on an HP $8453 \mathrm{UV}$-visible diode array spectrophotometer. $18 \mathrm{M} \Omega$ $\mathrm{cm}$ nanopure water was used in the preparation of reagents. XRD analysis was done using Bruker D8 Advance 800234-X-ray (9729) at $40 \mathrm{kV}$ and $40 \mathrm{~mA}$. Transmission electron microscopy (TEM) studies of AuNPs and AgNPs were performed on a JEOL TEM 2100F. The TEM experiments were conducted by adding a drop of the samples to the carbon-coated copper grid (Sigma-Aldrich, Milwaukee, WI) and then dried.

Seven different sizes and shapes of LTP-AgNPs were utilized for the antimicrobial and cytotoxic activities. The nanoparticles used include, LTP-AgNP1 (spherical, 9 nm), LTP-AgNP2 (spherical, $16 \mathrm{~nm}$ ), LTP-AgNP3 (spherical, $30 \mathrm{~nm}$ ), LTP-AgNP4 (spherical, $35 \mathrm{~nm}$ ), LTP-AgNP5 (quasi-spherical, $21 \mathrm{~nm}$ ), LTP-AgNP6 (quasi-spherical, $37 \mathrm{~nm}$ ) and LTP-AgNP7 (spherical, $21 \mathrm{~nm}$ ). The LTP-AuNPs were also synthesized by using LTP. The sizes and shapes of LTP-AuNPs were recorded and determined as follows: LTP-AuNP1 (spherical, $8 \mathrm{~nm}$ ), LTP-AuNP2 (spherical, $9 \mathrm{~nm}$ ), LTP-AuNP3 (spherical, $10 \mathrm{~nm}$ ), LTP-AuNP4 (cubic, 16 nm), LTP-AuNP5 (cubic, $20 \mathrm{~nm}$ ), LTP-AuNP6 (cubic, $372 \mathrm{~nm}$ ) and LTP-AuNP7 (cubic, $510 \mathrm{~nm}$ ). The representative size distribution of the AuNPs and AgNPs are presented in Figure 1, Figure 2, and Figure S1. Furthermore, the summary of the shapes and sizes of the synthesized AuNPs and AgNPs are presented in Table 2. 
Table 2. Summary of shapes and sizes of synthesized LTP-AgNPs and LTP-AuNPs.

\begin{tabular}{ccccc}
\hline $\begin{array}{c}\text { Parameters of } \\
\text { NP }\end{array}$ & \multicolumn{2}{c}{ LTP-AgNPs } & \multicolumn{2}{c}{ LTP-AuNPs } \\
\hline Shape & Spherical & Quasi-spherical & Spherical & Cubic \\
\hline Sizes $(\mathrm{nm})$ & $9,16,30,35$ & $21,37,21$ & $8,9,10$ & $16,20,372,510$ \\
\hline
\end{tabular}

Different concentrations of LTP-AgNPs and AuNPs ranging from $1 \mu \mathrm{M}$ to $280 \mu \mathrm{M}$ were prepared by dissolving the nanoparticles in nanopure water. Both LTP-AgNPs and LTP-AuNPs were compared to the LTP, LT, and LTP-AuNPs. The nanoparticles were tested for their antifungal activities in two ways: (i) precipitated and (ii) suspended forms. In the precipitated types, the precipitated AgNPs and suspended ones were utilized together while the suspended were the ones were obtained by filtering the stock AgNPs solution with $0.2 \mu \mathrm{m}$ filter, which eliminated any visible particles in the AgNPs solution. Only suspended AgNPs were utilized for the antibacterial and cytotoxicity tests.

\subsection{Antifungal Studies}

Turbidity/Agar Studies

Aspergillus nidulans $\mathrm{ATCC}^{\circledR}$ and Trichaptum biforme $\mathrm{ATCC}^{\circledR}$ were grown in peptone-yeast media while Penicillium italicum ATCC ${ }^{\circledR}$ and Colletotrichum gloeosporioides ATCC ${ }^{\circledR}$ were grown in dextrose-tryptone broth. A total $10^{3}$ spores were inoculated into $2-3 \mathrm{~mL}$ of fresh liquid media. A total of $30 \mathrm{mg} / \mathrm{mL}$ Yeast Peptone Dextrose (YPD) medium was autoclaved before the introduction of nanoparticles followed by A. nidulans or T. biforme. The preparation of liquid media made of dextrose-tryptone broth was conducted by following the manufacturer's procedure. The media containing fungi were vortexed at $8 \mathrm{~h}$ intervals to prevent any hyphae formation, and the incubation was performed in $25^{\circ} \mathrm{C}$ incubator for $48 \mathrm{~h}$. The turbidity of fungi was measured at $600 \mathrm{~nm}$ via HP 8453 UV-Vis spectrometry. In the case of solid culture, the fungal cells were performed on Nutrient Agar.

\subsection{Antibacterial Studies}

\subsubsection{Turbidity Studies}

The tested microorganisms were Pseudomonas aeruginosa ATCC ${ }^{\circledR}$, Aeromonas hydrophila ATCC ${ }^{\circledR}$, Escherichia coli $\mathrm{ATCC}^{\circledR}$, and Citrobacter freundii $\mathrm{ATCC}^{\circledR}$ as Gram $(-)$ bacteria, and Listeria monocytogenes ATCC ${ }^{\circledR}$ and Staphylococcus epidermidis ATCC ${ }^{\circledR}$ as Gram $(+)$ bacteria. Lysogeny broth (LB), a nutritionally rich medium, was used for the maintenance of the tested P. aeruginosa, A. hydrophilia, and L. monocytogenes while nutrient broth medium was used for E. coli, C. freundii, and S. epidermidis, respectively. All tests were repeated 2 times by 3 replicates of plates. All the microorganisms were propagated using broth media, and then nanoparticles were exposed to the organisms in their log phase. Incubation was carried out at $37^{\circ} \mathrm{C}$ for $18 \mathrm{~h}$. To prevent the microbial growth inhibited by nutrient scarcity, initial bacterial was kept at $10^{3} \mathrm{cfu} / \mathrm{mL}$; the observed growth inhibition was attributed to the presence of the nanoparticles. After $18 \mathrm{~h}$ incubation, UV-Vis was used to measure the optical density at $595 \mathrm{~nm}$ for the control and nanoparticle treated bacterial cultures. This was achieved by diluting the media twice with $50 \mathrm{mM}$ phosphate buffer saline at $\mathrm{pH} 7.4$

The experiments dealing with $A$. nidulans, T. biforme, P. italicum, C. gloeosporioides were performed in biosafety level 2 laboratory facilities located in the Department of Psychology at SUNY-Binghamton while L. monocytogenes, A. hydrophilia, and P. aeruginosa were conducted in the Department of Sustainable Bioproducts, College of Forest Resources and the Department of Basic Science in the College of Veterinary Medicine at Mississippi State University. 


\subsubsection{Bacterial Growth Kinetics in Response to Nanoparticle Treatment}

The LTP-AgNPs showed the best antibacterial activity was utilized at $10 \mu \mathrm{M}$ concentrations in order to monitor E. coli and S. epidermidis growth kinetics. Mueller Hinton Broth containing E. coli and S. epidermidis concentrations of $10^{3} \mathrm{cfu} / \mathrm{mL}$ were monitored for $24 \mathrm{~h}$. The $\mathrm{OD}_{600}$ measurements for both the E. coli and S. epidermidis were recorded and depicted as a graph in the results section.

\subsection{Cytotoxicity of the LTP-AgNPS}

Colon cancer cell line (ATCC ${ }^{\circledR}$ Caco-2 cells) and primary epithelial cell line (ATCC ${ }^{\circledR} 1730$ HUVEC cells) were used to evaluate the cytotoxicity of the LTP-AgNPs. Caco-2 cells were cultivated in Eagle-Modified-Essential-Medium containing $0.01 \mathrm{u} / \mathrm{g}$ insulin, $0.02 \%$ L-glutamine, 0.02\% non-essential amino acids and 9\% Fetal-bovine serum albumin. In contrast, HUVEC cells were cultured in Endothelial Cell Growth Media (Sigma-Aldrich, Cat. 211-500), which was used as purchased from the vendor.

A total of $150 \mu \mathrm{L}$ of $24 \mathrm{~h}$ incubated cells were plated in 96 -well plate at $37{ }^{\circ} \mathrm{C}, 5 \% \mathrm{CO}_{2}$ incubator, in which the initial confluence was 30\%, were treated with $50 \mu \mathrm{M}$ of the filtered LTP-AgNPs for $24 \mathrm{~h}$. A total of $9 \mu \mathrm{L}$ of PrestoBlueßfluorescent dye (Thermofisher, A13261) was added to each well and incubated at $37^{\circ} \mathrm{C}$ for $20 \mathrm{~min}$, which was then read with Biotek HT microplate-reader where excitation and emission wavelengths were $595 \mathrm{~nm}$ and $645 \mathrm{~nm}$, respectively.

\section{Conclusions}

This study focused on the size effect antimicrobial activity of LTP-AgNPs and LTP-AuNPs. The TEM and size distribution characterization of LTP-AgNPs and LTP-AuNPs showed different sizes and shapes. The antimicrobial activity of LTP-AgNPs and LTP-AuNPs against selected plant-based pathogens demonstrated that smaller sized LTP-AgNPs had the strongest antimicrobial activity. From these results, the LTP derived AgNPs have the potential to be used as antimicrobial agents. Furthermore, the low cytotoxicity of the colloidal LTP-AgNPs confirms that LTP-AgNPs could be applied as an antimicrobial remedy for infections caused by plant pathogens such as $P$. italicum and C. gloeosporioides. The antibacterial results revealed that the LTP-AgNPs inhibited the growth of both Gram (+) and Gram (-) bacteria; however, the inhibition was greater for Gram (+) bacteria. This study emphasizes cost-effective and eco-friendly antimicrobial agents as an alternative to conventionally used antimicrobial agents. LTP-AgNPs and LTP-AuNPs materials can find applications in remediation, drug delivery, and treatment against other pathogens.

Supplementary Materials: Figure S1: Histograms and the corresponding TEM micrographs (inset) for (A) LTP-AuNP1 (spherical, $8 \mathrm{~nm}$ ), (B) LTP-AgNP2 (spherical, $16 \mathrm{~nm}$ ), (C) LTP-AuNP3 (spherical, $10 \mathrm{~nm}$ ), (D) LTP-AuNP4 (cubic, $16 \mathrm{~nm}$ ), E) LTP-AgNP5 (quasi-spherical, $21 \mathrm{~nm}$ ), (F) LTP-AgNP6 (quasi-spherical, $37 \mathrm{~nm}$ ), Figure S2: (a) Control of A. nidulans, (b) (i) $1 \mu \mathrm{M}$, (ii) $2 \mu \mathrm{M}$ and (iii) $4 \mu \mathrm{M}$ LTP-AgNP1, (c) (i) $20 \mu \mathrm{g} / \mathrm{mL}$, (ii) $40 \mu \mathrm{g} / \mathrm{mL}$ and (iii) $80 \mu \mathrm{g} / \mathrm{mL}$ LTP, (d) (i) $36 \mu \mathrm{M}$, (ii) $72 \mu \mathrm{M}$ and (iii) $144 \mu \mathrm{M}$ LTP-AgNP2 after one week growth, Figure S3: (a) $36 \mu \mathrm{M}$ LTP-AgNP2 treated P. aeruginosa, (b) $18 \mu \mathrm{M}$ LTP-AgNP2 treated A. hydrophila, Figure S4: (a) $4 \mu \mathrm{M}$ LTP-AgNP1 treated A. hydrophila and (b) (i) $4.5 \mu \mathrm{M}$, (ii) $9 \mu \mathrm{M}$ and (iii) $18 \mu \mathrm{M}$ LTP-AgNP2 treated L. monocytogenes samples.

Author Contributions: Conceptualization, O.A.S.; F.J.O., and I.Y.; methodology, O.A.S.; F.J.O.; I.Y., (A.A.) Ali Akgul, and (A.A.) Ayfer Akgul.; performed experiment, I.Y.; F.J.O., (A.A.) Ali Akgul.; L.S. and (A.A.) Ayfer Akgul.; analyzed data, F.J.O.; I.Y.; writing—original draft preparation, F.J.O.; I.Y.; (A.A.) Ali Akgul and (A.A.) Ayfer Akgul; writing-review and editing, F.J.O., G.B.E. and O.A.S.; supervision, O.A.S.; project administration, O.A.S.; funding acquisition, O.A.S All authors have read and agreed to the published version of the manuscript.

Funding: This research was funded by the National Science Foundation Grant \#IOS- 1543944 and Bill \& Melinda Gates Foundation.

Conflicts of Interest: The authors declare no conflict of interest. 


\section{References}

1. Franci, G.; Falanga, A.; Galdiero, S.; Palomba, L.; Rai, M.; Morelli, G.; Galdiero, M. Silver nanoparticles as potential antibacterial agents. Molecules 2015, 20, 8856-88742. [CrossRef] [PubMed]

2. Pulit, J.; Banach, M.; Szczygłowska, R.; Bryk, M. Nanosilver against fungi. Silver nanoparticles as an effective biocidal factor. Acta Biochim. Pol. 2013, 60. [CrossRef]

3. Shahverdi, A.R.; Fakhimi, A.; Shahverdi, H.R.; Minaian, S. Synthesis and effect of silver nanoparticles on the antibacterial activity of different antibiotics against Staphylococcus aureus and Escherichia coli. Nanomed. Nanotechnol. Biol. Med. 2007, 3, 168-171. [CrossRef] [PubMed]

4. Zafar, N.; Shamaila, S.; Nazir, J.; Sharif, R.; Rafique, M.S.; Ul-Hasan, J.; Ammara, S.; Khalid, H. Antibacterial action of chemically synthesized and laser generated silver nanoparticles against human pathogenic bacteria. J. Mater. Sci. Technol. 2016, 32, 721-728. [CrossRef]

5. Wright, G.D. Bacterial resistance to antibiotics: Enzymatic degradation and modification. Adv. Drug Delivery Rev. 2005, 57, 1451-1470. [CrossRef]

6. Soenen, S.J.; Manshian, B.; Montenegro, J.M.; Amin, F.; Meermann, B.; Thiron, T.; Cornelissen, M.; Vanhaecke, F.; Doak, S.; Parak, W.J. Cytotoxic effects of gold nanoparticles: A multiparametric study. ACS Nano 2012, 6, 5767-5783. [CrossRef]

7. Chen, Y.-S.; Hung, Y.-C.; Liau, I.; Huang, G.S. Assessment of the in vivo toxicity of gold nanoparticles. Nanoscale Res. Lett. 2009, 4, 858. [CrossRef]

8. Bindhu, M.R.; Umadevi, M. Antibacterial activities of green synthesized gold nanoparticles. Mater. Lett. 2014, 120, 122-125. [CrossRef]

9. Liu, J.; Hurt, R.H. Ion release kinetics and particle persistence in aqueous nano-silver colloids. Environ. Sci. Technol. 2010, 44, 2169-2175. [CrossRef]

10. Reidy, B.; Haase, A.; Luch, A.; Dawson, K.A.; Lynch, I. Mechanisms of silver nanoparticle release, transformation and toxicity: A critical review of current knowledge and recommendations for future studies and applications. Materials 2013, 6, 2295-2350. [CrossRef]

11. Le Ouay, B.; Stellacci, F. Antibacterial activity of silver nanoparticles: A surface science insight. Nano today 2015, 10, 339-354. [CrossRef]

12. Bakirdere, S.; Yilmaz, M.T.; Tornuk, F.; Keyf, S.; Yilmaz, A.; Sagdic, O.; Kocabas, B. Molecular characterization of silver-stearate nanoparticles (AgStNPs): A hydrophobic and antimicrobial material against foodborne pathogens. Food Res. Int. 2015, 76, 439-448. [CrossRef] [PubMed]

13. Pal, S.; Tak, Y.K.; Song, J.M. Does the antibacterial activity of silver nanoparticles depend on the shape of the nanoparticle? A study of the gram-negative bacterium Escherichia coli. Appl. Environ. Microbiol. 2007, 73, 1712-1720. [CrossRef] [PubMed]

14. Raza, M.A.; Kanwal, Z.; Rauf, A.; Sabri, A.N.; Riaz, S.; Naseem, S. Size-and shape-dependent antibacterial studies of silver nanoparticles synthesized by wet chemical routes. Nanomaterials 2016, 6, 74. [CrossRef] [PubMed]

15. Majumdar, D.; Jung, K.-H.; Zhang, H.; Nannapaneni, S.; Wang, X.; Amin, A.R.; Chen, Z.; Shin, D.M. Luteolin nanoparticle in chemoprevention: In vitro and in vivo anticancer activity. Cancer Prev. Res. 2014, 7, 65-73. [CrossRef]

16. Jeong, Y.M.; Ha, J.H.; Park, S.N. Cytoprotective effects against UVA and physical properties of luteolin-loaded cationic solid lipid nanoparticle. J. Ind. Eng. Chem. 2016, 35, 54-62. [CrossRef]

17. Wang, Q.; Xie, M. Antibacterial activity and mechanism of Luteolin on Staphylococcus aureus. Wei Sheng Wu Хиe Bao = Acta Microbiologica Sinica 2010, 50, 1180-1184.

18. Eumkeb, G.; Siriwong, S.; Thumanu, K. Synergistic activity of luteolin and amoxicillin combination against amoxicillin-resistant Escherichia coli and mode of action. J. Photochem. Photobiol. B 2012, 117, 247-253. [CrossRef]

19. Osonga, F.J.; Le, P.; Luther, D.; Sakhaee, L.; Sadik, O.A. Water-based synthesis of gold and silver nanoparticles with cuboidal and spherical shapes using luteolin tetraphosphate at room temperature. Environ. Sci. 2018, 5, 917-932. [CrossRef]

20. Shankar, S.S.; Rai, A.; Ankamwar, B.; Singh, A.; Ahmad, A.; Sastry, M. Biological synthesis of triangular gold nanoprisms. Nat. Mater. 2004, 3, 482-488. [CrossRef] 
21. Osonga, F.J.; Yazgan, I.; Kariuki, V.; Luther, D.; Jimenez, A.; Le, P.; Sadik, O.A. Greener synthesis and characterization, antimicrobial and cytotoxicity studies of gold nanoparticles of novel shapes and sizes. RSC. Advances 2016, 6, 2302-2313. [CrossRef]

22. Bindhu, M.R.; Umadevi, M. Silver and gold nanoparticles for sensor and antibacterial applications. Spectrochim. Acta, Part A 2014, 128, 37-45. [CrossRef] [PubMed]

23. Yang, X.; Du, Y.; Li, D.; Lv, Z.; Wang, E. One-step synthesized silver micro-dendrites used as novel separation mediums and their applications in multi-DNA analysis. Chem. Commun. 2011, 47, 10581-10583. [CrossRef]

24. Philip, D. Green synthesis of gold and silver nanoparticles using Hibiscus rosa sinensis. Physica E 2010, 42, 1417-1424. [CrossRef]

25. Osonga, F.J.; Kariuki, V.M.; Yazgan, I.; Jimenez, A.; Luther, D.; Schulte, J.; Sadik, O.A. Synthesis and antibacterial characterization of sustainable nanosilver using naturally-derived macromolecules. Sci. Total Environ. 2016, 563, 977-986. [CrossRef]

26. Ahmad, N.; Sharma, S.; Alam, M.K.; Singh, V.; Shamsi, S.; Mehta, B.; Fatma, A. Rapid synthesis of silver nanoparticles using dried medicinal plant of basil. Colloids Surf. B 2010, 81, 81-86. [CrossRef]

27. Kim, D.; Jeong, S.; Moon, J. Synthesis of silver nanoparticles using the polyol process and the influence of precursor injection. Nanotechnology 2006, 17, 4019-4024. [CrossRef]

28. Goudarzi, M.; Mir, N.; Mousavi-Kamazani, M.; Bagheri, S.; Salavati-Niasari, M. Biosynthesis and characterization of silver nanoparticles prepared from two novel natural precursors by facile thermal decomposition methods. Sci. Rep. 2016, 6, 32539. [CrossRef]

29. Das, A.; Mukherjee, P.; Singla, S.K.; Guturu, P.; Frost, M.C.; Mukhopadhyay, D.; Shah, V.H.; Patra, C.R. Fabrication and characterization of an inorganic gold and silica nanoparticle mediated drug delivery system for nitric oxide. Nanotechnology 2010, 21, 305102. [CrossRef]

30. Elbeshehy, E.; Elazzazy, A.; Aggelis, G. Silver nanoparticles synthesis mediated by new isolates of Bacillus spp., nanoparticle characterization and their activity against Bean Yellow Mosaic Virus and human pathogens. Front Microbiol. 2015, 6, 453. [CrossRef]

31. Lamsal, K.; Kim, S.W.; Jung, J.H.; Kim, Y.S.; Kim, K.S.; Lee, Y.S. application of silver nanoparticles for the control of Colletotrichum species in vitro and pepper anthracnose disease in field. Mycobiology 2011, 39, 194-199. [CrossRef]

32. Lu, Z.; Rong, K.; Li, J.; Yang, H.; Chen, R. Size-dependent antibacterial activities of silver nanoparticles against oral anaerobic pathogenic bacteria. J. Mater. Sci. Mater. Med. 2013, 24, 1465-1471. [CrossRef]

33. Durán, N.; Durán, M.; De Jesus, M.B.; Seabra, A.B.; Fávaro, W.J.; Nakazato, G. Silver nanoparticles: A new view on mechanistic aspects on antimicrobial activity. Nanomed. Nanotechnol. Biol. Med. 2016, 12, 789-799. [CrossRef] [PubMed]

34. Lei, S.; Cheng, T.; Guo, Y.; Li, C.; Zhang, W.; Zhi, F. Somatostatin ameliorates lipopolysaccharide-induced tight junction damage via the ERK-MAPK pathway in caco2 cells. Eur. J. Cell Biol. 2014, 93, $299-307$. [CrossRef]

35. Verhoeckx, K.; Cotter, P.; López-Expósito, I.; Kleiveland, C.; Lea, T.; Mackie, A.; Requena, T.; Swiatecka, D.; Wichers, H. The Impact of Food Bioactives on Health: In vitro and Ex Vivo Models; Springer International Publishing AG: Cham, Switzerland, 2015.

36. Ciftci, H.; TÜRK, M.; TAMER, U.; Karahan, S.; Menemen, Y. Silver nanoparticles: Cytotoxic, apoptotic, and necrotic effects on MCF-7 cells. Turkish J. Biol. 2013, 37, 573-581. [CrossRef]

37. Liu, J.; Sonshine, D.A.; Shervani, S.; Hurt, R.H. Controlled release of biologically active silver from nanosilver surfaces. ACS Nano 2010, 4, 6903-6913. [CrossRef]

38. Gliga, A.R.; Skoglund, S.; Wallinder, I.O.; Fadeel, B.; Karlsson, H.L. Size-dependent cytotoxicity of silver nanoparticles in human lung cells: The role of cellular uptake, agglomeration and Ag release. Part. Fibre Toxicol. 2014, 11, 11. [CrossRef]

39. Lemire, J.A.; Harrison, J.J.; Turner, R.J. Antimicrobial activity of metals: Mechanisms, molecular targets and applications. Nat. Rev. Microbiol. 2013, 11, 371-384. [CrossRef]

40. Herman, A.; Herman, A.P. Nanoparticles as antimicrobial agents: Their toxicity and mechanisms of action. J. Nanosci. Nanotechnol. 2014, 14, 946-957. [CrossRef]

41. Shamaila, S.; Zafar, N.; Riaz, S.; Sharif, R.; Nazir, J.; Naseem, S. Gold nanoparticles: An efficient antimicrobial agent against enteric bacterial human pathogen. Nanomaterials 2016, 6, 71. [CrossRef] 
42. Kalishwaralal, K.; BarathManiKanth, S.; Pandian, S.R.K.; Deepak, V.; Gurunathan, S. Silver nanoparticles impede the biofilm formation by Pseudomonas aeruginosa and Staphylococcus epidermidis. Colloids Surf. B 2010, 79, 340-344. [CrossRef] [PubMed]

43. Barapatre, A.; Aadil, K.R.; Jha, H. Synergistic antibacterial and antibiofilm activity of silver nanoparticles biosynthesized by lignin-degrading fungus. Bioresources Bioprocess 2016, 3, 8. [CrossRef]

44. Wani, I.A.; Ahmad, T. Size and shape dependant antifungal activity of gold nanoparticles: A case study of Candida. Colloids Surf. B 2013, 101, 162-170. [CrossRef] [PubMed]

45. Tutaj, K.; Szlazak, R.; Szalapata, K.; Starzyk, J.; Luchowski, R.; Grudzinski, W.; Osinska-Jaroszuk, M.; Jarosz-Wilkolazka, A.; Szuster-Ciesielska, A.; Gruszecki, W.I. Amphotericin B-silver hybrid nanoparticles: Synthesis, properties and antifungal activity. Nanomed. Nanotechnol. Biol. Med. 2016, 12, 1095-1103. [CrossRef]

46. Fernández, J.G.; Fernández-Baldo, M.A.; Berni, E.; Camí, G.; Durán, N.; Raba, J.; Sanz, M.I. Production of silver nanoparticles using yeasts and evaluation of their antifungal activity against phytopathogenic fungi. Process Biochem. 2016, 51, 1306-1313. [CrossRef]

47. Ogar, A.; Tylko, G.; Turnau, K. Antifungal properties of silver nanoparticles against indoor mould growth. Sci. Total Environ. 2015, 521, 305-314. [CrossRef]

48. Xia, Z.-K.; Ma, Q.-H.; Li, S.-Y.; Zhang, D.-Q.; Cong, L.; Tian, Y.-L.; Yang, R.-Y. The antifungal effect of silver nanoparticles on Trichosporon asahii. J. Microbiol. Immunol. Infection 2016, 49, 182-188. [CrossRef]

49. Tao, N.; OuYang, Q.; Jia, L. Citral inhibits mycelial growth of Penicillium italicum by a membrane damage mechanism. Food Control 2014, 41, 116-121. [CrossRef]

50. Majeed, S.; bin Abdullah, M.S.; Dash, G.; Nanda, A. Facile and green synthesis of silver nanoparticles from Penicillium italicum and its antimicrobial property in combination with Sparfloxacin. J. Chem. Pharm. Res. 2015, 7, 27-33.

51. Osonga, F.J.; Akgul, A.; Yazgan, I.; Akgul, A.; Ontman, R.; Kariuki, V.M.; Eshun, G.B.; Sadik, O.A. Flavonoid-derived anisotropic silver nanoparticles inhibit growth and change the expression of virulence genes in Escherichia coli SM10. RSC Adv. 2018, 8, 4649-4661. [CrossRef]

52. Osonga, F.J.; Onyango, J.O.; Mwilu, S.K.; Noah, N.M.; Schulte, J.; An, M.; Sadik, O.A. Synthesis and characterization of novel flavonoid derivatives via sequential phosphorylation of quercetin. Tetrahedron Lett. 2017, 58, 1474-1479. [CrossRef]

Sample Availability: Samples of the compounds are not available from the authors.

(C) 2020 by the authors. Licensee MDPI, Basel, Switzerland. This article is an open access article distributed under the terms and conditions of the Creative Commons Attribution (CC BY) license (http://creativecommons.org/licenses/by/4.0/). 